\title{
The Russian translations of the Alcohol Use Disorders Identification Test (AUDIT): A document analysis and discussion of implementation challenges
}

\author{
Anna Bunova ${ }^{1}$, Maria Neufeld ${ }^{2-5}$, Carina Ferreira-Borges ${ }^{2}$, Evgeniy Bryun ${ }^{5}$, Eugenia Fadeeva ${ }^{6,7}$, Artyom Gil ${ }^{8}$, \\ Evgenia Koshkina $^{5}$, Aleksey Nadezhdin ${ }^{5}$, Elena Tetenova ${ }^{5}$, Konstantin Vyshinsky ${ }^{6}$, Elena Yurasova ${ }^{7}$, and \\ Jürgen Rehm ${ }^{2,3,8,10-14}$ \\ ${ }^{1}$ National Research Center for Preventive Medicine of the Ministry of Health of the Russian Federation, Petroverigskiy Pereulok 10, 101990, \\ Moscow, Russian Federation \\ 2 WHO European Office for Prevention and Control of Noncommunicable Diseases, Moscow, Leontyevsky Pereulok 9, 125009 Moscow, Russian \\ Federation \\ 3 Institute for Clinical Psychology and Psychotherapy, TU Dresden, Chemnitzer Str. 46, 01187 Dresden, Germany \\ ${ }^{4}$ Institute for Mental Health Policy Research, Centre for Addiction and Mental Health (CAMH), 33 Russell Street, Toronto, Ontario, Canada, M5S \\ $2 \mathrm{~S} 1$ \\ ${ }^{5}$ Moscow Research and Practical Centre for Narcology of the Department of Public Health, Lublinskaya Str. 37/1, 109390, Moscow, Russian \\ Federation \\ ${ }^{6}$ National Research Centre on Addictions - branch, V. Serbsky National Medical Research Centre for Psychiatry and Narcology of the Ministry \\ of Health of the Russian Federation, Maly Mogiltsevskiy Pereulok 3, 119002, Moscow, Russian Federation \\ ${ }^{7}$ Moscow State University of Psychology and Education, Sretenka Str. 29, 127051, Moscow, Russian Federation \\ ${ }^{8}$ I.M. Sechenov First Moscow State Medical University, Bolshaya Pirogovskaja Str., 19s1, 119146, Moscow, Russian Federation \\ 9 WHO Office in the Russian Federation, Leontyevsky Pereulok 9, 125009 Moscow, Russian Federation \\ ${ }^{10}$ Campbell Family Mental Health Research Institute, CAMH, 250 College Street, Toronto, Ontario, Canada, M5T 1R8 \\ ${ }^{11}$ Institute of Medical Science (IMS), University of Toronto, Medical Sciences Building, 1 King's College Circle, Room 2374, Toronto, Ontario, \\ Canada, M5S $1 \mathrm{~A} 8$ \\ ${ }^{12}$ Department of Psychiatry, University of Toronto, 250 College Street, 8th Floor, Toronto, Ontario, Canada, M5T 1R8 \\ ${ }^{13}$ Dalla Lana School of Public Health, University of Toronto, 155 College Street, 6th Floor, Toronto, Ontario, Canada, M5T 3M7 \\ ${ }^{14}$ Department of International Health Projects, Institute for Leadership and Health Management, I.M. Sechenov First Moscow State Medical \\ University, Trubetskaya str., 8, b. 2, 119992, Moscow, Russian Federation
}

\section{Abstract}

Aims: To analyze existing Russian translations of the Alcohol Use Disorders Identification Test (AUDIT) and their applicability in Russian-language populations.

Method: Document analysis of different Russian-language versions of the AUDIT and its shorter versions as identified in a systematic search.

Findings: A total of 122 Russian translations of the AUDIT or its shorter versions from Russia and other countries were included in the document analysis, 61 of which were unique versions. Across the translations, a series of inconsistencies was identified, most of which related to the first three consumption items and the concept of a standard drink. The identified problems appeared to have been caused by difficulties in adapting the tool to local drinking patterns and local beverage volumes. None of the analyzed sources mentioned systematic translation procedures according to a predetermined protocol.

Conclusions: Despite the fact that the AUDIT was developed as a standardized screening tool almost 30 years ago, there is still no official translation into the Russian language according to the commonly used procedures for the translation and adaptation of instruments. A systematic translation and validation appears to be urgently needed in order to have an internationally comparable AUDIT for research and clinical purposes in Russian-speaking populations.

Correspondence: Maria Neufeld, WHO European Office for Prevention and Control of Noncommunicable Diseases, Moscow, Leontyevsky Pereulok 9, 125009 Moscow, Russian Federation

Email: Neufeld.maria@googlemail.com

Financial support: This work was supported through a grant of the Russian Government to the WHO European Office for the Prevention and Control of Noncommunicable Diseases. This funding source had no role in the design of the study, its execution, analyses, interpretation of the data, or decision to submit results. Declaration of interest: None

Keywords: AUDIT, alcohol drinking, alcohol dependence, alcohol use disorders, cross-cultural research, instrument translation, Russia 


\section{Introduction}

Despite the recent downward trend in total alcohol consumption, the Russian Federation is still considered to be one of the heaviest-drinking countries in Europe and worldwide (World Health Organization, 2018). The local drinking patterns of irregular heavy episodic drinking and its detrimental effects on health, most importantly cardiovascular mortality, appear to have shaped the observed trends in mortality and life expectancy in Russia for the past decades (Nemtsov, Neufeld, \& Rehm, 2019; World Health Organization Regional Office for Europe, 2019).

In order to reduce alcohol-attributable burden, alcohol use disorders (AUDs), as well as per capita alcohol consumption at a population level, Russia has introduced various alcohol control measures in the past, such as higher alcohol pricing and restrictions on sale hours and advertisement (Khaltourina \& Korotayev, 2015; Kolosnitsyna, Sitdikov, \& Khorkina, 2014; Nemtsov et al., 2019; Neufeld \& Rehm, 2013), as well as specific measures against the use of unrecorded alcohol (i.e. alcohol which is consumed but not taxed as an alcoholic beverage; Neufeld \& Rehm, 2018a, 2018b). In 2016, with the help of the WHO European Region, the Russian Ministry of Health launched an initiative to implement screening and brief interventions (known as SBI) for alcohol problems in the primary health care (PHC) setting (World Health Organization Regional Office for Europe, 2017). SBI is an evidence-based practice used to identify, reduce, and prevent problematic use and abuse of alcohol and illicit drugs (including substance use disorders) (Babor \& Higgins-Biddle, 2001). Its goal is to identify individuals with potential or already manifested alcohol problems and motivate them to change their drinking behaviors at the PHC level, which is more accessible than specialized treatment settings.

The implementation of the SBI program within the Russian health-care system poses various specific challenges at the country level (Bunova et al., 2017; B.E. Gornyi, Kalinina, \& Bojcov, 2015; B.E. Gornyi, Kutumova, \& Kalinina, 2016), which are not unique when compared to the experiences of other countries which have implemented similar models (Anderson et al., 2017; Barry et al., 2004; Johnson, Jackson, Guillaume, Meier, \& Goyder, 2010). The availability of a quick, effective and reliable screening tool as part of the SBI program is a crucial cornerstone of the strategy's success since primary care physicians are not likely to use instruments that require special training or extra time during the medical interview, or in the recording of patients' accounts of their medical histories.

The Alcohol Use Disorders Identification Test (AUDIT) was developed by the WHO in the 1980 s as the main instrument of the SBI program (Babor \& Higgins-Biddle, 2001). It was validated in PHC facilities in six countries over four continents (Saunders, Aasland, Amundsen, \& Grant, 1993; Saunders, Aasland, Babor, de la Fuente, \& Grant, 1993). The AUDIT has established itself as an effective instrument in screening for hazardous and harmful alcohol consumption, which have been defined by the WHO as: (a) a pattern of alcohol use that increases the risk of harmful consequences for the user and (b) a pattern of use that is causing damage to health respectively (World Health Organization, 2019). However, the operationalizations of these definitions have been different in different countries, usually because of socalled "low risk drinking guidelines" (Furtwaengler \& de Visser, 2013) specific to each country.

To the best of our knowledge, there is no such definition in the Russian Federation besides the harmful use diagnosis of F10.1 in the Russian version of the ICD-10, which is only ever used in the diagnostic procedures of the highly specialized addiction services, the so-called "narcology" medical specialty - a sub-discipline of psychiatry. As for PHC facilities, "the risk of harmful use of alcohol" is addressed as one of several risk factors within the standard prophylactic medical examination, the so-called "dispanserization" effort available to the population in Russia (Garant.ru, 2019).

Dispanserization is a comprehensive population-based health screening program used in the Russian Federation for the early detection and prevention of chronic noncommunicable diseases as well as risk factors for their development. Rooted in the Soviet Semashko model of healthcare, with a focus on preventive services and health promotion within publicly owned polyclinics (the major providers of PHC in the case of Russia), dispanserization is routinely carried out covering the entire population and consists of a pre-screening and an in-depth consultation with respective specialists should any issues be detected. Dispanserization is carried out every three years for adults between 21 and 40 years and can be carried out every year starting from the age of 40 . At the same time, Russian adults are eligible for the so called "professional examination" every year, which is a shorter health check-up (Sheiman, Shishkin, \& Shevsky, 2018). However, there is no operational definition for the "risk of harmful alcohol use" within the legislative documents regulating these two processes. According to the existing law, the risks are assessed "according to the results of a survey (questionnaire)" and are coded as ICD-10 code Z72.1 (i.e., "Problems related to lifestyle: alcohol use"). The specific details for how the assessment is to be carried out are defined elsewhere, namely in the guidelines from the National Medical Research Center for Therapy and Preventive Medicine of the Ministry of Health. For alcohol, the most recent guidelines provide a Russian translation of the AUDIT with sex-specific cut-off values for hazardous and harmful alcohol use, which were copied from a Russian medical journal (Boytsov et al., 2017; Degtyareva, Kuznetsova, Plavinsky, \& Barinova, 2012). The hazardous and harmful alcohol use, however, are not defined within the AUDIT tool itself.

Considering that the AUDIT has not been validated for the Russian Federation, the lack of widely recognized and accepted definitions of hazardous and harmful alcohol use poses serious challenges for its implementation. However, the Ministry of Health has recently initiated a large-scale validation study of the AUDIT for use in the Russian Federation, also in response to the concerns expressed by some narcologists that the AUDIT would not adequately 
capture the specific drinking patterns in Russian-language populations (Rehm et al., 2020; Neufeld et al., 2021a). Over 60 Russian-language translations of the AUDIT were identified worldwide as a result of the first step of this validation effort (Neufeld et al., 2021b). The present contribution is part of this validation effort and provides a document analysis of the various translations of the AUDIT used in Russia and Russian-speaking populations in other countries. It discusses the reasons for the discrepancies found between the various translations and the resulting implementation challenges for both the AUDIT and the SBI program.

\section{Methods}

The registered search protocol and further details on the methodology of the systematic search for the Russian translations of the AUDIT, and the extraction procedures, can be found in Neufeld and colleagues (2021). The extracted materials were analyzed by two researchers via a document analysis, a systematic procedure for reviewing and evaluating documents or any other communication artefacts.

\section{Results}

A clustering of the different versions was performed, where the translations were grouped according to their initial source and format and thus their potential impact and national and international reach (see Table 1). As indicated above, a total of 61 unique Russian-language translations of the AUDIT were identified across all media types and countries. However, in some cases the same version was found in a source from the Russian Federation as well as in a source from another country/international source, which led to some double counting in Table 1.

\section{Table 1}

Overview of identified versions of the Russian-language AUDIT (including AUDIT-C and FAST)

\begin{tabular}{lcc}
\hline Sources from the Russian Federation & $\begin{array}{c}\text { Total of identified } \\
\text { versions }^{-}\end{array}$ & $\begin{array}{c}\text { Unique } \\
\text { identified }^{\mathbf{b}} \text { versions }^{-}\end{array}$ \\
\hline $\begin{array}{l}\text { Official recommendations and guidelines (clinical, methodical, protocols, } \\
\text { instructions) }\end{array}$ & 17 \\
Websites, information materials & 20 & 11 \\
Monographs, books, textbooks, presentations & 13 & 13 \\
Articles, research projects, dissertations, conference materials & 29 & 10 \\
\end{tabular}

\begin{tabular}{lcc}
\hline Sources from other countries & (Belarus, Estonia, Finland, Israel, Lithuania, Sweden, Switzerland, Ukraine, USA, Sweden) \\
\hline HO publications and documents* & 7 & 6 \\
Official recommendations and guidelines (clinical, methodical, protocols, & 5 & 4 \\
instructions) & 20 & 17 \\
Websites, information materials & 4 & 4 \\
Monographs, books, textbooks, presentations & 7 & 4 \\
Articles, research projects, dissertations, conference materials & 7 \\
\hline
\end{tabular}

${ }^{\mathrm{a}}$ The sources from other countries also include the Russian translation of the AUDIT from the WHO website for the European

Region as well as other Russian-language publications of the WHO Regional Office for Europe.

${ }^{\mathrm{b}}$ In some cases, the same version was found in a source from the Russian Federation as well as in a source from another

country/international source, which is why the numbers provided in the right column of the table do not add up to 61 in total.

Below we describe the main differences found across the different translation versions as well as across the different types of sources. While the focus of the present analysis was largely on the differences between translations, in order to identify the most important conceptual issues with the Russian AUDIT and to inform a systematic validation approach, we also compared the differences between sources in some instances. We believe that this approach is useful in identifying possible application and implementation issues with the Russian version of the AUDIT, for instance in its role in the Russian healthcare system. An overview of all source materials and the performed clustering can be found in the Appendix (Table 1A).

\section{Main differences: Consumption items and definitions of standard drinks}

The main differences were found in the first three test items, specifically their wording and representations of consumed volumes of alcohol and/or standard drinks (SDs).

Various translations $(n=29)$, did not define the SD at all or at least its definition was not featured in the original source material. The rest featured definitions of the SD in different and often multiple forms. A total of 19 sources featured the SD definition in the accompanying material, but not on the test itself - for instance, when the AUDIT was found in a publication, but the SD definition and the scoring scheme were featured in the Appendix but not in the publication itself. A total of 35 sources featured an in-text explanation/definition of the SD that was part of the test 
instructions. A total of 28 sources defined the SD in the second and third consumption item (i.e. when asking for the typical intake on a day or the frequency of heavy alcohol intake). A total of 10 versions used additional pictorial material to illustrate SDs, 10 sources featured a formula for converting individual consumption quantities into SDs, and 36 sources featured frequency-volume conversion tables for different types of alcoholic beverages.

A subset of versions defined an SD not in grams of pure alcohol but as specific volumes of alcoholic beverages, such as $100 \mathrm{ml}$ of wine or $30 \mathrm{ml}$ of spirits. Two versions (Aleksandrov, Kaminskaja, \& Dokukina, 2014; Shurygina, 2009) featured conversion tables that translated frequency and volume of consumption of certain beverages directly into the AUDIT score, thus leaving the concept of the SD completely out of the equation.
While most of the versions that used the SD in the second and third test items defined an SD as being 10 grams, there were three versions which used the standard United States American SD of 14 grams (Balashova et al., 2005) while a version from Ukraine found in three sources used a 13-gram SD (Gaidabrus, 2014; Linskij, Minko, \& Artemchuk, 2009; Linskij et al., 2010). The vast majority of the sources featured the "classic" 10-item version of the AUDIT, while some sources featured the short forms, namely the Fast Alcohol Screening Test (FAST), the AUDIT-4, the AUDIT$\mathrm{C}$ as well as a combination of AUDIT and AUDIT-C. Remarkably, a total of six sources were identified, in which the AUDIT-C and the full AUDIT were featured jointly in the document, but differed in their wording. For an overview of the SD sizes and test versions, see Table 2.

Table 2

Overview of identified sources of the Russian-language AUDIT (including AUDIT-C and FAST).

\begin{tabular}{|c|c|c|c|}
\hline SD sizes & $\begin{array}{c}\text { Total of identified } \\
\text { sources }\end{array}$ & $\begin{array}{c}\text { Specific version of the } \\
\text { test }\end{array}$ & $\begin{array}{c}\text { Total of identified } \\
\text { sources }\end{array}$ \\
\hline SD size is not specified in the source material & 29 & AUDIT (10 items) & 100 \\
\hline $\mathrm{SD}=10 \mathrm{~g}$ & 39 & AUDIT-C & 3 \\
\hline $\mathrm{SD}=13 \mathrm{~g}$ & 3 & AUDIT-4 & 1 \\
\hline $\mathrm{SD}=14 \mathrm{~g}$ & 3 & FAST & 1 \\
\hline \multirow[t]{3}{*}{$\begin{array}{l}\text { SD defined in the additional materials (either as } 10 \\
\text { grams of pure alcohol or in volumes of specific } \\
\text { beverages) }\end{array}$} & 48 & $\begin{array}{l}\text { AUDIT + AUDIT-C } \\
\text { (same version in one } \\
\text { source) }\end{array}$ & 9 \\
\hline & & $\begin{array}{l}\text { AUDIT + AUDIT-C } \\
\text { (different versions in } \\
\text { one source) }\end{array}$ & 6 \\
\hline & & $\begin{array}{c}\text { AUDIT + FAST (in one } \\
\text { source) }\end{array}$ & 2 \\
\hline
\end{tabular}

\section{Main inconsistencies: Varying SD counts and answer options}

In addition to the different representations of an SD, various other differences were identified between the versions. In some cases, these differences seemed to be obvious transcription mistakes or copy-and-paste errors since the same flaws noted in test questions or answer options were found in various translations. For instance, a total of 29 sources featured an incomplete SD count in the answer option to the second consumption item: an option to select 9 SDs was not provided in the answer category, and therefore in these versions respondents could only choose between consuming 7-8 SDs or $\geq 10$ SDs. Moreover, two documents (Boytsov et al., 2017; Degtyareva et al., 2012) featured an alternate SD count in the second consumption item, which went as high as 13 SDs or more for the last answer option, without providing any empirical evidence for this deviation from the original item. For instance, 1-4 SDs (where a standard drink was defined as 10 grams of pure alcohol), consumed on a typical day of drinking would result in a score of zero in this version, yet in the original AUDIT, consumption of 3-4 SDs would result in an AUDIT score of 1. The third item of this version screened for the consumption of $\geq 7$ SDs on a single occasion, whereas consumption of $\geq 6$ SDs was assessed in the original AUDIT. Considering that this version of the AUDIT (Boytsov et al., 2017; Degtyareva et al., 2012) provides the legislative base for the provision of dispanserization (early detection and prevention of chronic noncommunicable diseases) in Russia, this inconsistency is particularly alarming.

Furthermore, some of the versions expressing SDs in volumes of the commonly consumed beverages in the second or third consumption items differed from one other. For instance, one Russian source defined $1 \mathrm{SD}$ as a $500 \mathrm{ml}$ bottle of beer (Stop-alko.info, 2019), while another version - a research protocol of a large-scale study in the Russian Federation (Cook et al., 2018) - defined 2 SDs as $500 \mathrm{ml}$ of beer. Yet another Russian-language source from Switzerland (Kusnachtpractice.ch, 2019) defined $500 \mathrm{ml}$ of beer as being equivalent to $2.5 \mathrm{SDs}$.

A similar issue of alternating beverage volumes was identified in some frequency-volume conversion tables. For instance, some conversion tables suggested that 100-200 ml of wine would correspond to 1-2 SDs, while other versions suggested that $100-150 \mathrm{ml}$ of wine are equal to $1-2$ SDs and 
one table implied that both, $75-150 \mathrm{ml}$ of wine with $11-13 \%$ alcohol content as well as $75-150 \mathrm{ml}$ of fortified wine with 17-20\% alcohol content would correspond to 1-2 SDs (Muntyan, 2018). Moreover, the latter version had an obvious error in its scoring scheme for the table (i.e., a scale from 0 to 5 omitted the marker for the value of 2 ).

Another problem with the conversion tables was that they formed incomplete intervals. For example, an individual consuming $75 \mathrm{ml}$ of vodka on a single drinking occasion could not formally be assigned to any of the provided categories (30-60 $\mathrm{ml}$ for $1-2$ SDs or $90-120 \mathrm{ml}$ for 3-4 SDs) and could therefore be classified as either having an AUDIT score of 0 or 1 for this item.

Only the two above-mentioned conversion tables without an SD count (Aleksandrov et al., 2014; Shurygina, 2009) provided intervals without numeric "gaps." In these two cases, the categories were exhaustive, yet they were not mutually exclusive, since a person with $75 \mathrm{ml}$ of spirits consumption could be equally assigned to two different categories with this approach, leaving the selection of the category up to the interviewer. Various other issues were identified, such as the wrong assignment of AUDIT scores to items or alternating numbers of SDs asked in the third consumption item.

Varying thresholds for hazardous and harmful use or possible alcohol use disorders

While most of the analyzed translations featured the same thresholds for hazardous consumption (total score >7), harmful consumption (16-19), and possible alcohol use disorder (AUD) $(\geq 20)$ as the original international version (Babor \& Higgins-Biddle, 2001; Saunders, Aasland, Amundsen, et al., 1993), some translations suggested lower cut-offs. For instance, the Russian information portal on medical psychology (Medpsy.ru, 2019) stated that a score of $\geq 15$ would indicate possible AUD. A literature review on different diagnostic methods available for assessing alcohol use in Russia reported on the "clinical experiences" of the AUDIT application in more than 1,000 patients and stated that the instrument was found to be "convenient, simple and highly informative" (Petrov, 2003). It also stated that individuals scoring $\geq 15$ were likely to meet the criteria of current alcohol dependence. This same low threshold was found in a Russian-language version from Israel (Ashdod.muni.il, 2019) and, most remarkably, in a WHO publication, which stated that a score of $\geq 15$ for men and a score of $\geq 13$ for women indicated possible alcohol dependence (Graham, Parkes, \& McAuley, 2013).

Differing cut-offs were also found across different AUDIT$\mathrm{C}$ versions. For instance, the above- mentioned guidelines of the National Medical Research Center for Therapy and Preventive Medicine for the dispanserization screening process (Boytsov et al., 2017; Degtyareva et al., 2012; Gornyj \& Kalinina, 2018) recommended AUDIT-C cut-offs of $\geq 4$ for men and $\geq 3$ for women, which were found to be optimal thresholds based on empirical evidence from international studies (Bradley et al., 2003; Bradley et al., 2007; Bush, Kivlahan, McDonell, Fihn, \& Bradley, 1998), and were also in line with recommendations from narcology specialists (Brjun et al., 2016). However, we have identified at least two versions of the AUDIT-C with a much higher cut-off of $\geq 5$ for both sexes in Russian publications - one of them was found in a practical guide for the prevention of fetal alcohol spectrum disorders (FASD) (Fadeeva, 2019) and the other in guidelines for the prevention of alcohol abuse in females (Fadeeva, Grechanaja, Vyshinskij, \& Nenast'eva, 2019).

\section{Discussion}

To our knowledge, the large number of Russian translations of the AUDIT and the variety among them is an unprecedented case for one country in the global application of the instrument. Although a variety of AUDITs exist in other languages, these translated versions appear to be supported by accompanying validation studies or are at least based on other empirical evidence (Gache et al., 2005; Leung \& Arthur, 2000; Tsai, Tsai, Chen, \& Liu, 2005). For instance, a systematic review of the Chinese translations of the AUDIT reported that five teams from Beijing, Tibet, Taiwan and Hong Kong have developed region-specific translations, cultural adaptations and validation procedures for the AUDIT for their local context (Li, Babor, Hao, \& Chen, 2011). In the Russian Federation, however, no such validation effort could be found (World Health Organization, 2019). On the contrary, various research and practitioner groups from different settings seem to routinely use different versions of the AUDIT, which are apparently the result of individual project-based translations rather than of a coordinated effort, which would involve a standardized process of translation and adaptation of instruments (World Health Organization, 2019b).

Overall, the observed and documented translation differences pertained to the first three consumption items (AUDIT-C), whereas the translation of the remaining two dimensions of the test, i.e., test items on alcohol dependence as well as alcohol-related problems and harm, were much more consistent and only linguistic in nature. Unlike the repeating issues related to the quantification of standard drinks, the only problem that was observed for the remaining scale was in the wrong scoring of the two last test items in a handful of translations, which seemed to be the result of a simple copy-and-paste error (Azimova, 2015; Kostjukevich, 2016; Trusova \& Krupickij, 2012; Yusupova \& Lishuta, 2015).

Therefore, our findings suggest that the main difficulty of the AUDIT lies in capturing the specific drinking patterns that prevail in Russia and Russian-language populations and their effects on alcohol-attributable burden (Shield \& Rehm, 2015). The concept of a "standard drink" is not widely used in the Russian language and seems to be a specific obstacle to the application of the AUDIT in Russian. However, the concept of an SD is not familiar to many countries and languages and it also differs substantially in size between countries, even within Europe. For instance, according to a 2014 survey of the Joint Action on Reducing Alcohol Related Harm (RARHA), different national definitions of an SD across 27 countries of the European Union (EU) exist, which may also reflect differences in drinking cultures 
across Europe (Mongan \& Long, 2015). Although 11 of the surveyed EU countries operated with an SD of 10 grams of pure alcohol, the size differed considerably for the remaining 16 countries, with the United Kingdom's SD having the lowest number of grams of alcohol (8 grams) and Austria's SD having the highest (20 grams).

The analysis has revealed that the main differences of the various translations were linked to the SD concept and the various ways and approaches of conveying its meaning in the test, such as using additional tables, explanatory notes or pictures. This suggests that the main problem of the AUDIT in Russian language seems to be the lack of a systematic adaptation of the unknown SD concept rather than to any problem related to the Russian language specifically.

Many different translations emanated from other countries outside the Russian Federation, which may also reflect local drinking patterns, as well as local and specific needs within varying health-care settings in different countries, rather than inconsistencies within the instrument itself. Moreover, most of the inconsistent or erroneous versions of the test (i.e. versions with incomplete SD counts and obvious copy-andpaste errors) came from the Russian Federation and not from other countries, which suggests problems with implementation and application rather than issues related to the psychometric qualities of the AUDIT.

The varying cut-offs for AUDIT and AUDIT-C within the Russian health-care system as well as the lack of official definitions of hazardous or harmful alcohol use support this interpretation. The only document featuring a definition of "risk of hazardous alcohol use" is the previously mentioned guideline document for the dispanserization protocol (Boytsov et al., 2017), which inexplicably contains a very high SD count and therefore de-facto defines hazardous and harmful drinking in Russia at a level much higher than, for instance, the medium-risk drinking levels for chronic disease from the European Medicines Agency (2010).

\section{Limitations}

Undertaking a qualitative document analysis of differing translations at such a detailed level requires researchers to interpret concepts, which can introduce bias through individual interpretations of the source material. This is why a collaborative effort is required at every step of the process, beginning with defining inclusion criteria, all the way through to interpretation. A considerable degree of immersion into the individual studies is required to achieve synthesis, which was difficult to accomplish in our case given the broad objectives of the review, the broad inclusion criteria, and the considerable number of inconsistencies found in the source materials for the various translations. Also, a considerable number of unique AUDIT translations were not identified through databases, but through contact made with individual experts. This may not only have introduced additional bias, but also hints at the potential existence of various other translations that may not have been identified by our search strategy (Neufeld et al., 2021).

\section{Conclusion}

The main goal of this qualitative analysis was to identify the most common issues of the Russian translation of the AUDIT across different countries and implementation fields in order to inform future steps of the validation procedure.

The existence of the various Russian translations of the AUDIT in the Russian Federation as well as other countries highlights the need for an alcohol screening instrument for various Russian-language populations outside of the Russian Federation. However, the documented differences and inconsistencies in the consumption items and cut-offs as well as the identified different versions in guideline documents even within one country suggest that, to date, the translation efforts seem not to have been well coordinated. For instance, none of the identified 61 unique translations mentioned any systematic adaptation procedures, which would have followed a predefined protocol and included specific procedures for back translation, revising, pilot testing and cognitive debriefing with an expert panel, although there are clearly defined procedures for all of these (World Health Organization, 2019). The lack of this systematic effort reduces the comparability of research carried out with the use of the AUDIT among Russian-language populations and poses a risk to the successful implementation of the AUDIT and the broader SBI initiative.

There is a clear need for a systematic translation, adaptation and validation process for the AUDIT in the Russian Federation from which other countries with large numbers of Russian-speaking citizens would greatly benefit. The present analysis suggests that special attention needs to be paid to the assessment of the first three consumption items, and that an empirical validation of Russia-specific AUDIT thresholds for the different risk levels is urgently needed.

\section{Ethics Committee Approval}

The presented work is based on a systematic review of published data, and thus did not require ethical review according to Russian ethics conventions. 


\section{Register of Systematic Reviews (PROSPERO)}

Details of the systematic review have been published in the PROSPERO register. The registration number of the record is: CRD42019128059.

\section{References}

Aleksandrov, A. A., Kaminskaja, Y. M., \& Dokukina, T. V. (2014). Metod profilaktiki alkogol'noj zavisimosti v social'no neblagopoluchnyh sem'jah. Instrukcija po primineniju. [Method of prevention of alcohol dependence in socially disadvantaged families. Instructions for application.] Republican Scientific and Practical Center for Mental Health. Minsk. Retrieved from https://www.mentalhealth.by/media/doc/Prof alk.pdf

Anderson, P., O'Donnell, A., Kaner, E., Gual, A., Schulte, B., Perez Gomez, A., ... Rehm, J. (2017). Scaling-up primary health care-based prevention and management of heavy drinking at the municipal level in middleincome countries in Latin America: Background and protocol for a three-country quasi-experimental study. F1000Research, 6 ,

311.

https://doi.org/10.12688/f1000research.11173.3

Ashdod.muni.il. (2019). Test na alkogolizm VOZ [Alcoholism test WHO.] Retrieved from https://www.ashdod.muni.il/media/16486395/\%D7\%A 9\%D7\%90\%D7\%9C\%D7\%95\%D7\%A0\%D7\%99\%D7 $\% 9 \mathrm{D}-$

\%D7\%9C\%D7\%91\%D7\%93\%D7\%99\%D7\%A7\%D7 $\% 94-$

\%D7\%A2\%D7\%A6\%D7\%9E\%D7\%99\%D7\%AA$\% \mathrm{D} 7 \% 91 \% \mathrm{D} 7 \% \mathrm{~A} 9 \% \mathrm{D} 7 \% \mathrm{~A} 4 \% \mathrm{D} 7 \% 94-$ \%D7\%94\%D7\%A8\%D7\%95\%D7\%A1\%D7\%99\%D7 $\%$ AA-6.pdf.

Azimova, J. J. (2015). Zloupotreblenie alkogolem i alkogol'naja zavisimost': Brosit' pit' nel'zja prodolzhat'? [Alcohol abuse and alcohol dependence: Can you stop drinking?] 30/10/2020 from https://medi.ru/docplus/f441406.htm.pdf

Babor, T. F., \& Higgins-Biddle, J. C. (2001). Brief Intervention for hazardous and harmful drinking: A manual for use in primary care. Retrieved from: https://apps.who.int/iris/bitstream/handle/10665/67210/ WHO_MSD_MSB_01.6b.pdf;jsessionid=5812A3237B 1F09035117AC1F35A7C95F? sequence $=1$

Balashova, T. N., Isurina, G. L., Pal'chik, A. B., Shapkajc, V. A., Ioffe, A. M., \& Regentova, A. J. (2005). Pomoshh' pacientam, kotorye slishkom mnogo p'jut: Klinicheskoe rukovodstvo. [Helping patients who drink too much: A clinical guideline.] Research Group on FAS Prevention in Russia. Retrieved from http://netfas.net/pro/drunks.pdf

Barry, K. L., Blow, F. C., Willenbring, M. L., McCormick, R., Brockmann, L. M., \& Visnic, S. (2004). Use of alcohol screening and brief interventions in primary care settings: Implementation and barriers. Substance Abuse, 25(1), 27-36. https://doi.org/10.1300/J465v25n01_05
Boytsov, S. A., Drapkina, O. M., Kalinina, A. M., Ipatov, P. V., Vergazova E.K., Gambaryan M.G., ... Mkhitaryan E. A. (2017). Organizacija provedenija dispanserizacii opredelennyh grupp vzroslogo naselenija. Metodicheskie rekomendacii po prakticheskoj realizacii prikaza Minzdrava Rossii ot 26 oktjabrja 2017 g., № $869 \mathrm{n} \ll \mathrm{Ob}$ utverzhdenii porjadka provedenija dispanserizacii opredelennyh grupp vzroslogo naselenija», Moskva. [The organization of the clinical examination of certain groups of the adult population. Guidelines for the practical implementation of the order of the Ministry of Health of Russia dated October 26, 2017, No. 869n "On approval of the procedure for the clinical examination of certain groups of the adult population"], Moscow. Retrieved from http://docs.cntd.ru/document/556623052

Bradley, K. A., Bush, K. R., Epler, A. J., Dobie, D. J., Davis, T. M., Sporleder, J. L., ... Kivlahan, D. R. (2003). Two brief alcohol-screening tests from the Alcohol Use Disorders Identification Test (AUDIT): Validation in a female Veterans Affairs patient population. Archives of Internal Medicine, 163(7), 821-829. https://doi.org/10.1001/archinte.163.7.821

Bradley, K. A., DeBenedetti, A. F., Volk, R. J., Williams, E. C., Frank, D., \& Kivlahan, D. R. (2007). AUDIT-C as a brief screen for alcohol misuse in primary care. Alcoholism: Clinical \& Experimental Research, 31(7), 1208-1217. https://doi.org/10.1111/j.15300277.2007.00403.x

Brjun, E. A., Agibalova, T. V., Volkov, A. V., Egorov, V. F., Koshkina, E. A., Melik-Gusejnov, D. V., ... Shamakina, I. J. (2016). Metodicheskie rekomendacii «Novyj podhod $\mathrm{k}$ terapii alkogol'noj zavisimosti, osnovannyj na ispol'zovanii metoda snizhenija potreblenija alkogolja» 2016 god [Methodical recommendations. "A new approach to the treatment of alcohol dependence, based on the use of a method to reduce alcohol consumption" 2016.] Retrieved from http://www.opnd89.ru/assets/files/novosti/13.05.16/met hod-rec.pdf

Bunova, A. S., Gornyi, B. E., Dubovoi, I. I., Dolgova, S. V., Odincova, E. V., Palij, I. A., \& Kalinina, A. M. (2017). Otnoshenie medicinskih rabotnikov pervichnogo zvena zdravoohranenija $\mathrm{k}$ profilaktike problemnogo potreblenija alkogolja [Primary health care workers' attitude towards prevention of problematic alcohol consumption.] The Russian Journal of Preventive Medicine, 20(5), 37-41.

Bush, K., Kivlahan, D. R., McDonell, M. B., Fihn, S. D., \& Bradley, K. A. (1998). The AUDIT alcohol consumption questions (AUDIT-C): An effective brief screening test for problem drinking. Archives of Internal Medicine, 158(16), 1789-1795. https://doi.org/10.1001/archinte.158.16.1789

Cook, S., Malyutina, S., Kudryavtsev, A. V., Averina, M., Bobrova, N., Boytsov, S., ... Leon, D. A. (2018). Know Your Heart: Rationale, design and conduct of a crosssectional study of cardiovascular structure, function and risk factors in 4500 men and women aged 35-69 years from two Russian cities, 2015-18. Wellcome Open Research, 3 , https://doi.org/10.12688/wellcomeopenres.14619.2 
Degtyareva, L., Kuznetsova, O., Plavinsky, S., \& Barinova, A. (2012). Ispol'zovanie metodiki modifikacii povedeniya pacienta pri opasnom i vrednom upotreblenii alkogolya.[Using the method of modifying the patient's behavior with dangerous and harmful use of alcohol.] Russian Family Foctor, 16, 55-64.

European Medicines Agency. (2010). Guideline on the development of medicinal products for the treatment of alcohol dependence. Retrieved from https://www.ema.europa.eu/documents/scientificguideline/guideline-development-medicinal-productstreatment-alcohol-dependence_en.pdf

Fadeeva, E. (2019). Profilaktika fetal'nogo alkogol'nogo sindroma. Prakticheskoe posobie. [Prevention of fetal alcohol syndrome. Practical guide.] Center for Prevention of Drug Addiction, St. Petersburg.

Fadeeva, G., Grechanaja, T., Vyshinskij, K., \& Nenast'eva, A. (2019). Genderno - specifichnaja profilaktika potreblenija alkogolja $i$ narkotikov. Rukovodstvo po genderno-specificheskoj profilaktike [Gender-specific prevention of alcohol and drug use. Guidelines for Gender-Specific Prevention.] ROBO "CPN". St. Petersburg.

Furtwaengler, N. A., \& de Visser, R. O. (2013). Lack of international consensus in low-risk drinking guidelines. Drug and Alcohol Review, 32(1), 11-18. https://doi.org/10.1111/j.1465-3362.2012.00475.x

Gache, P., Michaud, P., Landry, U., Accietto, C., Arfaoui, S., Wenger, O., \& Daeppen, J. B. (2005). The Alcohol Use Disorders Identification Test (AUDIT) as a screening tool for excessive drinking in primary care: Reliability and validity of a French version. Alcoholism: Clinical \& Experimental Research, 29(11), 2001-2007. https://doi.org/10.1097/01.alc.0000187034.58955.64

Gaidabrus, A. V. (2014). Rasstrojstva vsledstvie upotreblenija alkogolja u byvshih voennosluzhashhih «v zerkale» testa AUDIT. [Disorders due to the use of alcohol by former military personnel "in the mirror" of the AUDIT test.] Ukrainian Bulletin of Psychoneurology, 22(1), 114-119.

Garant.ru. (2019). Prikaz Ministerstva zdravoohranenija RF ot 26 oktjabrja 2017 g. \# 869n "Ob utverzhdenii porjadka provedenija dispanserizacii opredelennyh grupp vzroslogo naselenija"[Order of the Ministry of Health of the Russian Federation of October 26, 2017 No. 869n "On approval of the procedure for conducting clinical examination of certain groups of the adult population".] Retrieved

from https://www.garant.ru/products/ipo/prime/doc/7173031 4/

Gornyi, B. E., Kalinina, A. M., \& Bojcov, S. A. (2015). Vyjavlenie lic $\mathrm{s}$ riskom pagubnogo upotreblenija alkogolja $\mathrm{v}$ hode dispanserizacii: Metodologicheskie aspekty [Detection of persons at risk for harmful alcohol consumption during prophylactic medical examinations: Methodological aspects.] The Russian Journal of Preventive Medicine, 18(4), 12-16.

Gornyi, B. E., Kutumova, O. J., \& Kalinina, A. M. (2016). Voprosy organizacii pervichnoj mediko-sanitarnoj pomoshhi licam, upotrebljajushhim alkogol's vrednymi posledstvijami. [Issues of organizing primary health care for people consuming alcohol with harmful consequences.] The Russian Journal of Preventive Medicine, 19(5), 22-26.

Gornyi, B. E., \& Kalinina, A. M. (2018). Povyshenie motivacii $\mathrm{k}$ otkazu ot upotreblenija alkogolja $\mathrm{v}$ hode profilakticheskogo konsul'tirovanija pri okazanii pervichnoj mediko-sanitarnoj pomoshhi zhenshhinam reproduktivnogo vozrasta. Metodicheskie rekomendacii. [Increasing motivation to quit alcohol consumption in the course of preventive counseling as part of the provision of primary health care to women of reproductive age. Guidelines.] National Medical Research Center for Therapy and Preventive Medicine of the Ministry of Healthcare of the Russian Federation, Moscow. Retrieved from http://www.hospitalvrn.ru/files/docs/o_napravlenii_metodicheskih_rekome ndacij__ot_golub.pdf

Graham, L., Parkes, T., \& McAuley, A. (2013). Problemy, svjazannye s alkogolem, $\mathrm{v}$ sisteme ugolovnogo pravosudija: Vozmozhnost' dlja vmeshatel'stva. [Alcohol problems in the criminal justice system: Opportunity for intervention.] Retrieved from http://www.euro.who.int/_data/assets/pdf_file/0007/18 7081/e96751r.pdf?ua=1

Johnson, M., Jackson, R., Guillaume, L., Meier, P., \& Goyder, E. (2010). Barriers and facilitators to implementing screening and brief intervention for alcohol misuse: A systematic review of qualitative evidence. Journal of Public Health, 33(3), 412-421. https://doi.org/10.1093/pubmed/fdq095

Khaltourina, D., \& Korotayev, A. (2015). Effects of specific alcohol control policy measures on alcohol-related mortality in Russia from 1998 to 2013. Alcohol and Alcoholism, 50(5), 588-601. https://doi.org/10.1093/alcalc/agv042

Kolosnitsyna, M., Sitdikov, M., \& Khorkina, N. (2014). Availability restrictions and alcohol consumption: A case of restricted hours of alcohol sales in Russian regions. 2014, 3(3), 193-201. International Journal of Alcohol and Drug Research. https://doi.org/10.7895/ijadr.v3i3.154

Kostjukevich, O. I. (2016). Alkogol'nyj gepatit: Sovremennye algoritmy diagnostiki i lechenija. [Alcoholic hepatitis: Modern algorithms for diagnosis and treatment.] Russian Medical Journal, 24(3), 177182.

Kusnachtpractice.ch. (2019). Projdite test na priznaki alkogolizma i uznajte rezul'tat prjamo sejchas. [Take a test for signs of alcoholism and find out the result right now.] Retrieved from https://kusnachtpractice.com/ru/self-tests/alcoholism

Leung, S. F., \& Arthur, D. (2000). The alcohol use disorders identification test (AUDIT): Validation of an instrument for enhancing nursing practice in Hong Kong. International Journal of Nursing Studies, 37(1), 57-64. https://doi.org/10.1016/s0020-7489(99)00052-8

Li, Q., Babor, T. F., Hao, W., \& Chen, X. (2011). The Chinese translations of Alcohol Use Disorders Identification Test (AUDIT) in China: A systematic review. Alcohol and Alcoholism, 46(4), 416-423. https://doi.org/10.1093/alcalc/agr012

Linskij, I. V., Minko, A. I., \& Artemchuk, A. F. (2009). Metod kompleksnoj ocenki addiktivnogo statusa 
individa $\mathrm{i}$ populjacii s pomoshh'ju sistemy AUDITpodobnyh testov. [The method of complex assessment of the addictive status of an individual and the population using the AUDIT-like system of tests.] Bulletin of Psychiatry and Psychopharmacotherapy, 2, 56-70.

Linskij, N. V., Minko, A. N., Grinevich, E. V., Markova, M. V., Musienko, G. A., Shalashov, V. V., \& \& Minko, A. A. (2010). Addiktivnyj status i metod ego kompleksnoj ocenki pri pomoshhi sistemy AUDIT-podobnyh testov [Addictive status and method of its integrated assessment using the AUDIT-like test system.] Mental Health, 8(6), 33-45.

Medpsy.ru. (2019). Informacionnyjportal «Medicinskaja psihologija», 2019. AUDIT (AUDIT - Alcohol Use Disorders Identification Test). [InformationPortal“Medical Psychology:, 2019. AUDIT (AUDIT - Alcohol Use Disorders Identification Test).] Retrieved

from http://www.medpsy.ru/dictionary/metod 01 001.php

Mongan, D., \& Long, J. (2015). Standard drink measures throughout Europe: Peoples' understanding of standard drinks and their use in drinking guidelines, alcohol survey and labelling. Retrieved from https://www.drugsandalcohol.ie/30419/

Muntyan, Y. V. (2018). Estimation of availability for formation of dependence on psychoactive substances in Surgut school students editorial board. In: R.V. Raspopov \& A.A. Zverev. Proceedings of the XVI International Scientific and Practical Conference of the public movement "Union of the Approval and Preservation of Sobriety 'The Sober Ural'"

Nemtsov, A., Neufeld, M., \& Rehm, J. (2019). Are trends in alcohol consumption and cause-specific mortality in Russia between 1990 and 2017 the result of alcohol policy measures? Journal of Studies on Alcohol and Drugs, 80(5), 489-498. Retrieved from https://www.ncbi.nlm.nih.gov/pubmed/31603746

Neufeld M., Bunova A., Ferreira-Borges C., Bryun E., Fadeeva E., Gil A., ... Rehm, J. (2021a). The Alcohol Use Disorders Identification Test (AUDIT) in the Russian language - a systematic review of validation efforts and application challenges. Preprint. Retrieved from https://www.researchsquare.com/article/rs$\underline{154267 / \mathrm{v} 1}$

Neufeld M., Rehm J., Bunova A., Gil A., Gornyi B., Rovira P., ... Ferreira-Borges C. (2021b). Validation of a screening test for alcohol use, the Russian Federation. Bulletin of the World Health Organization. 2021;99:496-505. http://dx.doi.org/10.2471/BLT.20.273227

Neufeld, M., \& Rehm, J. (2013). Alcohol consumption and mortality in Russia since 2000: Are there any changes following the alcohol policy changes starting in 2006? Alcohol and Alcoholism, 48(2), 222-230. https://doi.org/10.1093/alcalc/ags134

Neufeld, M., \& Rehm, J. (2018a). Effectiveness of policy changes to reduce harm from unrecorded alcohol in Russia between 2005 and now. International Journal of Drug Policy, 51, 1-9. https://doi.org/10.1016/j.drugpo.2017.09.006

Neufeld, M., \& Rehm, J. (2018b). Newest policy developments regarding surrogate alcohol consumption in Russia. International Journal of Drug Policy, 54, 5859. https://doi.org/10.1016/j.drugpo.2017.11.013

Petrov, D. V. (2003). Diagnostika, lechenie i profilaktika rasstrojstv, vyzvannyh upotrebleniem alkogolja. [Diagnosis, treatment and prevention of disorders caused by alcohol.] Yaroslavl: Kancler.

Rehm, J., Neufeld, M., Yurasova, E., Bunova, A., Gil, A., Gornyi, B., ... \& Kalinina, A. (2020). Adaptation of and protocol for the validation of the alcohol use disorders identification test (AUDIT) in the Russian Federation for use in primary healthcare. Alcohol and Alcoholism, 55(6), 624-630. https://doi.org/10.1093/alcalc/agaa067

Saunders, J. B., Aasland, O. G., Amundsen, A., \& Grant, M. (1993). Alcohol consumption and related problems among primary health care patients: WHO collaborative project on early detection of persons with harmful alcohol consumption-I. Addiction, 88, 349-362. https://doi.org/10.1111/j.1360-0443.1993.tb00822.x

Saunders, J. B., Aasland, O. G., Babor, T. F., de la Fuente, J. R., \& Grant, M. (1993). Development of the Alcohol Use Disorders Identification Test (AUDIT): WHO collaborative project on early detection of persons with harmful alcohol consumption-II. Addiction, 88(6), 791$804 . \quad$ Retrieved from http://www.ncbi.nlm.nih.gov/pubmed/8329970

Sheiman, I., Shishkin, S., \& Shevsky, V. (2018). The evolving Semashko model of primary health care: The case of the Russian Federation. Risk Management and Healthcare Policy, 11, 209-220. https://doi.org/10.2147/rmhp.S168399

Shield, K., \& Rehm, J. (2015). Russia-specific relative risks and their effects on the estimated alcohol-attributable burden of disease. BMC Public Health, 15(1), 482. https://doi.org/10.1186/s12889-015-1818-y

Shurygina, Y. Y. (2009). Nauchno-prakticheskie osnovy zdorov'ja (Uchebnoe posobie). [Scientific and practical foundations of health. (A textbook).] Retrieved from https://valeologija.ru/knigi/osnovi-zdorovya-uchebnoeposobie-shurigina

Stop-alko.info. (2019). AUDIT (10 VOPROSOV) [AUDIT (10 questions)] Retrieved from https://stopalko.info/tests/audit.htm 1

Trusova, A. V., \& Krupickij, E. M. (2012). Primenenie narkologicheskogo konsul'tirovanija $i$ kratkoj psihokorrekcionnoj intervencii $v$ kompleksnoj profilaktike zavisimosti ot alkogolja $v$ rabote brigad pervichnogo zvena ambulatornoj $i$ stacionarnoj medicinskoj pomoshhi. Metodicheskie rekomendacii. [The use of drug addiction counseling and brief psychocorrectional intervention in the complex prevention of alcohol dependence in the work of teams of the primary care of outpatient and inpatient medical care. Guidelines.] Saint Petersburg, Russia: Bekhterev Psychoneurological Institute.

Tsai, M. C., Tsai, Y. F., Chen, C. Y., \& Liu, C. Y. (2005). Alcohol Use Disorders Identification Test (AUDIT): Establishment of cut-off scores in a hospitalized Chinese population. Alcoholism: Clinical \& Experimental Research, 29(1), 53-57. https://doi.org/10.1097/01.alc.0000151986.96710.e0

World Health Organization. (2018). Global status report on alcohol and health 2018 Retrieved from 
https://www.who.int/substance_abuse/publications/glob al alcohol report/en/

World Health Organization. (2019). Lexicon of Alcohol and Drug Terms Published by the World Health Organization. Retrieved from https://www.who.int/substance_abuse/terminology/who lexicon/en/

World Health Organization Regional Office for Europe. (2017). Training toolkit for alcohol screening and brief intervention tested for use in the Russian Federation. Retrieved from http://www.euro.who.int/en/countries/russianfederation/news/news/2017/01/training-toolkit-foralcohol-screening-and-brief-intervention-tested-for-usein-the-russian-federation

World Health Organization Regional Office for Europe. (2019). Reduction of harmful alcohol use and alcoholattributable mortality. A case study of the effects of alcohol control measures in the Russian Federation. Retrieved from: https://www.euro.who.int/en/publications/abstracts/alco hol-policy-impact-case-study-the-effects-of-alcoholcontrol-measures-on-mortality-and-life-expectancy-inthe-russian-federation-2019

Yusupova, A. O., \& Lishuta, A. S. (2015). Alkogol' i narushenija serdechnogo ritma. [Alcohol and heart rhythm disorders.] Rational Pharmacotherapy in Cardiology, 11(3), 317-326. 